\title{
The combined application of FTIR microspectroscopy and ToF-SIMS imaging in the study of prostate cancer
}

\author{
Ehsan Gazi, ${ }^{a}$ John Dwyer, ${ }^{a}$ Nicholas Lockyer, ${ }^{a}$ Peter Gardner, ${ }^{* a}$ John C. Vickerman, ${ }^{a}$ \\ Jaleel Miyan, ${ }^{b}$ Claire A. Hart, ${ }^{c}$ Mick Brown, ${ }^{c}$ Jonathan H. Shanks ${ }^{c}$ and Noel Clarke ${ }^{c}$ \\ a Department of Chemistry, UMIST, Manchester, UK M60 1QD \\ ${ }^{b}$ Department of Biomolecular Sciences, UMIST, Manchester, UK M60 1QD \\ ${ }^{c}$ CRC Paterson Institute, Christie Hospital NHS Trust, Manchester, UK M20 4BX
}

Received 2nd May 2003, Accepted 9th July 2003

First published as an Advance Article on the web 19th September 2003

At present, a prognosis for prostate cancer $(\mathrm{CaP})$ is determined by its accurate assessment of disease grade and stage. Histopathological typing using the Gleason grading system is the most universally accepted approach for grading $\mathrm{CaP}$ and provides an indication as to the aggressiveness of the tumour at the time of presentation. However, this system is based upon a visual criterion of pattern recognition that is operator dependent and subject to intra- and inter-observer variability, which can result in inappropriate patient management. Thus, there is a need for a molecular based diagnostic technique to grade tissue samples in a reliable and reproducible manner. In this paper we report a prototype diagnostic classifier for Gleason graded $\mathrm{CaP}$ tissue, based upon the integration of FTIR microspectroscopy with linear discriminant analysis (LDA). Blind testing of this model demonstrates $80 \%$ agreement of FTIR-LDA grade to histology, for the specimens analysed. We also study the effects of connective tissue absorption upon the area ratio of peaks at $A_{1030 \mathrm{~cm}^{-1}} / A_{1080 \mathrm{~cm}^{-1}}$ which we use as a criterion to biospectroscopically map and distinguish areas of benign from malignant tissue. In addition, imaging time-of-flight secondary ion mass spectrometry (ToF-SIMS) has been applied to study freeze-dried, freeze-fractured prostate cancer cells in vitro. Preliminary results demonstrate localisation of various species including $\mathrm{K}, \mathrm{Ca}$ and $\mathrm{Mg}$ within the cytoplasm that are present at millimolar concentrations and vital to cell physiology. The soft ionisation technique employed also permits for molecular information to be obtained and this has been used to evaluate chemically, different fracture planes within the analysis area.

\section{Introduction}

Prostate cancer $(\mathrm{CaP})$ is the second most common cause of cancer related death in males within the United Kingdom. ${ }^{1}$ At present, a prognosis for $\mathrm{CaP}$ is determined by its accurate assessment of disease grade and stage.

To this end, the universally accepted method in histopathological grading is through the use of the Gleason grading system. ${ }^{2}$ This method in grading sub-divides the complex continuum of glandular architectural changes that occur during prostate cancer progression into five visually distinct grades that can be viewed under an optical microscope. The Gleason score is derived from the sum of the primary and secondary Gleason grades (GG) that may co-exist within the same 
specimen, thus resulting in scores between 2 and 10. Reports have demonstrated a significant difference in prognosis at Gleason scores of 6 and 7 whereby a score 7 tumour is associated with a higher progression risk than those who exhibit scores 5 or $6 .{ }^{3-5}$ However, there are limitations in reproducibility in a specific grade due to intra- and inter-observer variability. These preclude its acceptance as a single prognostic tool. ${ }^{6-8}$ Methods to increase the accuracy of Gleason scoring by pathologists have been suggested and these rely on standardising the visual criterion of pattern recognition on which the system is currently based., ${ }^{9,10}$

Alternatively, within the last decade the use of vibrational microspectroscopy, Fourier transform infrared (FTIR) and Raman, combined with imaging technology and neural networking algorithms have been much to the forefront in the development of practical diagnostic tools for the detection and cytopathological grading of various neoplasms. ${ }^{11}$ These techniques allow for the means to probe the complex biochemical changes that occur within tumour cells during malignancy, resulting in spectral patterns that may be characteristic of the disease state. The major advantage of these techniques is the non-reductionist approach to molecular diagnosis since all phenotypic features are analysed simultaneously.

Previously, our group has applied linear discriminant analysis (LDA) to infrared (IR) spectra derived from $\mathrm{CaP}$ tissue of GGs two to five, as a means of constructing an operator independent diagnostic algorithm for CaP grading. ${ }^{12}$ In addition, we have demonstrated the use of FTIR-microspectroscopy for in vitro biochemical specific imaging of $\mathrm{CaP}$ tissue coexisting with benign tissue and extracellular matrix using a simple diagnostic criterion, the peak area ratio of $A_{1030 \mathrm{~cm}^{-1}} / A_{1080 \mathrm{~cm}^{-1}}$ (indicative of cell metabolic activity). ${ }^{12}$ Our goal is to combine IR imaging technology to LDA cluster analysis as a rapid, inexpensive screening process to $\mathrm{CaP}$ assessment that can be readily integrated into current histopathological practices.

Although IR spectroscopy provides a great deal of biochemical information from a cell, the functional group vibrations that arise are not specific to any one particular component of the cell matrix. In addition, inorganic ions play an integral role in processes such as cell proliferation or apoptosis ${ }^{13}$ and regulation of cell metabolism. ${ }^{14}$ However, these ions cannot be studied by FTIR. Therefore, we have adopted the use of imaging time-of-flight secondary ion mass spectrometry (ToF-SIMS) to address these issues and to further our understanding of CaP aetiology.

The SIMS technique allows for the localisation and identification of target molecular species from the outermost layers of a submicrometer scale surface. These unique capabilities of SIMS have been successfully applied to biological systems for the examination of intercellular ion fluxes in cancer cells, ${ }^{15,16}$ pharmacological studies of drug distribution in human tissue, ${ }^{17}$ and investigations into model membrane dynamics ${ }^{18}$ among others.

The SIMS methodology employed in the present study falls under the regime of static SIMS in which a low primary ion flux of $<1 \times 10^{13}$ ions $\mathrm{cm}^{-2}$ is utilized to desorb and ionise species from the sample surface. This approach permits the detection of intact molecular species as well as inorganic ions. Using this surface sensitive technique it is possible to analyse several sections of a cell if fractured. ${ }^{19}$

In this present study we further our evaluation of an FTIR-LDA diagnostic algorithm for CaP grading, through blind testing of several biopsy specimens taken from different patients. In addition, we report our preliminary findings using imaging ToF-SIMS on freeze-fractured, freeze-dried prostate cancer cell lines.

\section{Material and methods}

\section{Primary tissue preparation and sampling for FTIR}

Twelve archived CaP tissue biopsy specimens were obtained as paraffin-embedded blocks (Paterson Institute for Cancer Research). These were sectioned at $10 \mu \mathrm{m}$ using a Leica RM2155 Microtome and mounted onto $\mathrm{BaF}_{2}$ plates (Linkam Scientific Ltd.). The sections were then washed with Citroclear for $6 \mathrm{~min}$ to remove the paraffin and washed with cold $\left(4^{\circ} \mathrm{C}\right)$ acetone for a further $6 \mathrm{~min}$ and then air-dried under ambient conditions before FTIR analysis.

Targeted IR spectra of benign and malignant prostate epithelial cells within the tissue matrix involved the collection of serial sections, from the specimen, one of which was mounted onto $\mathrm{BaF}_{2}$ 
with the adjacent section mounted onto a glass slide and stained using hematoxylin and eosin (H\&E).

It was then possible to use the anatomical features identified from the H\&E section as landmarks that allowed for the positioning of the IR beam on the complimentary section mounted onto the $\mathrm{BaF}_{2}$ plate. In the present study, areas for analysis and Gleason grades were assigned by an experienced histopathologist (J.H.S).

\section{FTIR- microspectroscopy and spectral-imaging}

FTIR spectra of Gleason graded CaP primary prostate tissue were collected in transmission mode using a Nicolet Magna system 550 spectrometer equipped with a liquid nitrogen cooled MCT/A detector and a $\mathrm{KBr}$ beam splitter. The spectrometer is attached to a microscope equipped with a television camera in order to view optical images of the sampling area and a programmable computerized $x / y$ stage. The size of the lower aperture (confocal arrangement) is set so that it matches the projected image of the upper aperture. Spectra were taken from $\mathrm{CaP}$ tissue using an aperture size of $60 \times 60 \mu \mathrm{m}^{2}$.

FTIR spectra represent an average of 512 scans in the wavenumber range $750-4000 \mathrm{~cm}^{-1}$ with a resolution of $4 \mathrm{~cm}^{-1}$. Background scans were obtained from a region of no sample and ratioed against the sample spectrum.

FTIR spectral imaging of primary prostate tissue was collected in transmission mode using a Bio-Rad FTS 6000 spectrometer equipped with a liquid nitrogen cooled $64 \times 64$ focal plane array detector (spatial resolution $6.5 \times 6.5 \mu \mathrm{m}^{2}$ ). Each spectrum was recorded with a single scan, in step scan mode at $16 \mathrm{~cm}^{-1}$ resolution.

\section{PC-3 cell line preparation for ToF-SIMS}

Cell lines were prepared on single crystal silicon or stainless steel substrates. Human prostate cell carcinoma (PC-3) was cultured in Ham's F12, 7\% FCS and $2 \mathrm{mM}$ L-glutamine. ${ }^{20}$ Culture was grown at $37^{\circ} \mathrm{C}$ in a humidified atmosphere of $5 \% \mathrm{CO}_{2}$ in air until confluent. L-Glutamine suspended $4.5 \mu \mathrm{m}$ copolymer microspheres (50000 beads per $100 \mathrm{~mm}$ plastic dish) were added to the steel cell wafer and allowed to settle acting as spacers to prevent cells being crushed, during the sandwich-fracture technique. The microspheres were inert to the cells and their size reflects the estimated height of the nucleus from the steel substrate. A second substrate was placed on top of the cultured cells forming a sandwich, which could be prised apart after fast freezing to reveal fractured cell surfaces.

PC-3 cells were also grown on a single silicon wafer using the above conditions and stored under liquid nitrogen. This specimen was used to analyse the surface chemistry of intact cells (see Results and discussion).

All reagents were purchased from Sigma-Aldridge, Poole, UK. All tissue culture media were obtained from Invitrogen, Paisley, UK with the exception of Ham's F12 media (PAA Laboratories, Austria). Foetal calf serum (FCS) was supplied by Labtech International Ltd., Uckfield, Sussex, UK. Microspheres were purchased from Duke Scientific, California.

\section{Sandwich freeze fracture and freeze drying for ToF-SIMS}

The steel piece containing the cells was removed from the growth medium and rinsed with distilled water. A new and clean steel wafer piece $(12 \times 6 \times 0.25 \mathrm{~mm})$ was placed on top (shard), sandwiching the cells between two surfaces. Using liquid nitrogen cooled forceps, the sandwich was fast frozen in slushed liquid nitrogen-cooled, liquid isopentane. The sandwich was then transferred to a $1 \mathrm{ml}$ cryovial (Nalgene Co, USA) and stored in liquid nitrogen. Under liquid nitrogen, tweezers were used to pry apart the shard from the lower substrate and fracture the cells. The cell culture substrates (steel and silicon) were then freeze dried at $10^{-1}$ Torr overnight.

\section{ToF-SIMS analysis}

The custom-built "BioToF" mass spectrometer was used for experiments. ${ }^{21}$ The freeze-dried specimens were placed on a copper stub and introduced into the sample analysis chamber, 
maintained at $1 \times 10^{-8}$ Torr. ToF-SIMS analysis was performed under the following conditions. A liquid metal gallium primary ion source (Ionoptika Ltd, UK), with beam energy of $15 \mathrm{keV}$ (1.7 nA continuous current, focused beam diameter $c a .1 \mu \mathrm{m}$ ) was used to bombard the specimen surface. The ion beam was digitally scanned over the analysis area with the sample held at +2.5 $\mathrm{keV}$. Positive secondary ions were extracted into the vertical reflectron ToF-MS analyser and detected using a microchannel plate assembly. ToF-SIMS spectra and images were collected in positive ion mode. ToF-SIMS images were acquired at $256 \times 256$ pixel resolution.

\section{Optical fluorescence microscopy}

Following ToF-SIMS analysis, the freeze-dried specimen was stained with Vectashield (Vector Laboratories Inc., California) containing propidium iodide. When bound to nucleic acids, a red fluorescence is observed at $\sim 615 \mathrm{~nm}$. These images were captured using a Leica DM LB microscope.

\section{Data processing}

FTIR. Data processing immediately after spectrum acquisition was carried out using the OMNIC v.5.1a software, which included the Atlus video capturing program. The Microcal Origin v.4.1 program was used for further processing and performed baseline correction (rubber band algorithm) and normalization of spectra relative to the amide I peak $\left(\sim 1650 \mathrm{~cm}^{-1}\right)$. Normalized spectra were used to correct for differences in path length of the IR beam and the number of cells analysed within the chosen aperture size.

Origin also allowed for the deconvolution of specific bands. The aim of this operation is to resolve the underlying and overlapping peaks present as a composite of a broad peak. The procedure mathematically enhances the resolution of the spectrum, using an iterative statistical curve fitting of symmetric Gaussian peaks to the straight, baseline-corrected spectra. Linear discrimination analysis (LDA) of IR spectral data was carried out using SPSS Release 11.0.0. It was found that the band region between $1480 \mathrm{~cm}^{-1}$ and $1000 \mathrm{~cm}^{-1}$ provided separation of IR spectral data, acquired from primary tissue, into well defined clusters.

ToF-SIMS. The experimental ToF-SIMS data were processed using software developed in collaboration with Professor Winograd's group at Penn State. The program allows for the manipulation of contrast to distinguish between different intensities of secondary ion emissions within the sampling area. In the ToF-SIMS image the detected secondary ion signal over the selected mass range is displayed on a thermal intensity scale, ranging from black (low intensity), through to red, orange, yellow and white (high intensity). Selected mass images can also be displayed on red, blue or green scales and overlayed to provide contrast images. Standard ToF-SIMS reference spectra ${ }^{22}$ were used to identify signals from common surface contaminants such as polydimethylsiloxane (PDMS).

\section{Results and discussion}

\section{FTIR analysis}

Connective tissue influence on $A_{1030 \mathrm{~cm}^{-1}} / A_{1080 \mathrm{~cm}^{-1}}$ criterion. The peaks at $1030 \mathrm{~cm}^{-1}$ and $1080 \mathrm{~cm}^{-1}$ correspond to $v_{\mathrm{s}}(\mathrm{C}-\mathrm{O})$ and $v_{\mathrm{s}}\left(\mathrm{PO}_{2}\right)^{-}$, respectively. These functional group vibrations arise from IR absorption of the glycogen $\left(1030 \mathrm{~cm}^{-1}\right)$ and phosphate $\left(1080 \mathrm{~cm}^{-1}\right)$ components of the cell. The area ratio of these peaks, $A_{1030 \mathrm{~cm}^{-1}} / A_{1080 \mathrm{~cm}^{-1}}$, is indicative of the metabolic turnover of the cell, since glycogen stores are consumed and utilised for the generation of ATP energy, which in turn is used in the phosphorylation of proteins. This process is up regulated in proliferating $\mathrm{CaP}$ cells in contrast to normal prostate epithelial cells that are terminally differentiated and where glycogen consumption is relatively low.

Previously, we have used the $A_{1030 \mathrm{~cm}^{-1}} / A_{1080 \mathrm{~cm}^{-1}}$ as a criterion to distinguish between normal, benign and malignant prostate tissue. ${ }^{12}$ These results show that malignant, benign and normal tissue generate $A_{1030 \mathrm{~cm}^{-1}} / A_{1080 \mathrm{~cm}^{-1}}$ values of $\leq 0.5,0.6-0.8$ and $\geq 1.0$, respectively, Fig. 1 . 


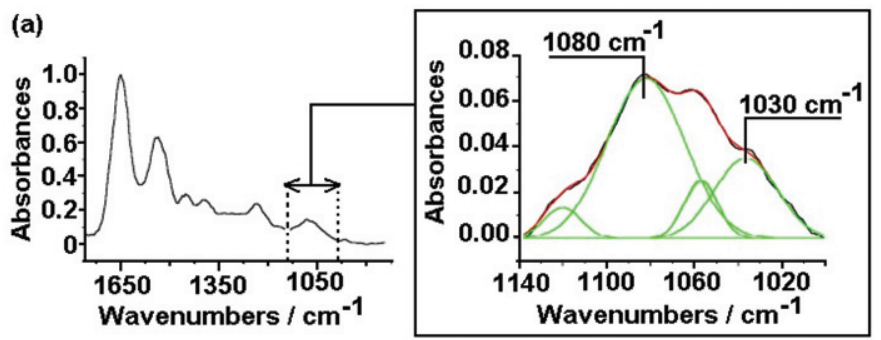

(b)

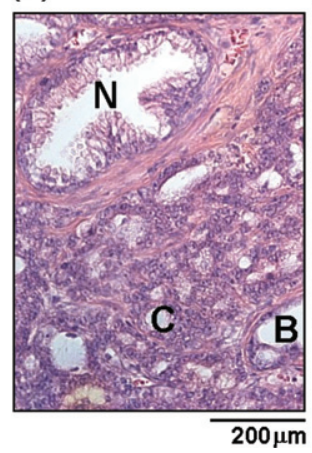

(c)

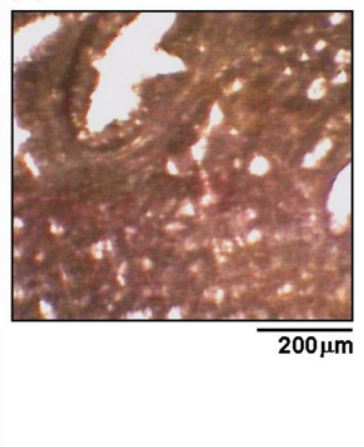

(d)

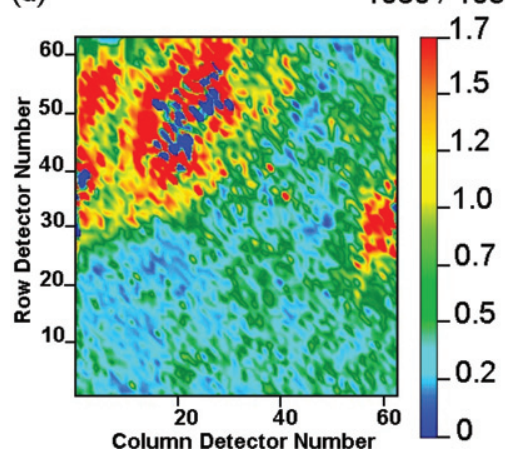

Fig. 1 (a) Raw FTIR spectrum of malignant epithelial tissue. Inset shows the deconvoluted peaks at 1030 $\mathrm{cm}^{-1}$ and $1080 \mathrm{~cm}^{-1}$ after baseline correction and normalisation of the band region between $1140 \mathrm{~cm}^{-1}$ and 1000 $\mathrm{cm}^{-1}$ in the raw spectrum. (b) A H\&E stained prostate tissue section exhibiting a normal prostate gland, N, malignant epithelial tissue, $\mathrm{C}$, and a benign atrophic gland, B. (c) Complimentary serial section mounted on $\mathrm{BaF}_{2}$ for FTIR analysis. Slight variations in anatomical features occur in the serial section. (d) FTIR simulated image of prostate tissue showing the distribution of $A_{1030 \mathrm{~cm}^{-1}} / A_{1080 \mathrm{~cm}^{-1}}$ values.

The $A_{1030 \mathrm{~cm}^{-1}} / A_{1080 \mathrm{~cm}^{-1}}$ criterion can, however, be influenced by absorbencies associated with connective tissue (CT). Targeted IR spectra of unstained malignant tissue is dependent upon a comparison with an H\&E stained section and phase contrast images as viewed through the FTIR microscope. Although this technique is successful at positioning the IR beam at any desired location within the tissue, small amounts of $\mathrm{CT}$ within malignant areas are not readily identifiable by phase contrast or by H\&E comparison. Histochemical staining using Masson's trichrome (TRI) reveals that even within locations of densely packed $\mathrm{CaP}$ cells, variable amounts of intervening $\mathrm{CT}$ are present as shown in Fig. 2.

In a typical IR spectrum of tissue, the band region between $\sim 1000 \mathrm{~cm}^{-1}$ and $\sim 1140 \mathrm{~cm}^{-1}$ is composed of functional group vibrations arising from cellular components (RNA, nucleic acids, phosphorylated proteins, lipids and glycogen). Since, CT consists of predominately protein in the form of collagen type VII with little cellular material, the value of the peak intensity ratio $I_{1080 \mathrm{~cm}^{-1}} /$ $I_{1240 \mathrm{~cm}^{-1}}$ is small compared to that exhibited by epithelial tissue, Fig. 3(e). An FTIR instrument incorporating a focal plane array detector (FAD) can be used to biochemically map the $I_{1080 \mathrm{~cm}^{-1}} /$ $I_{1240 \mathrm{~cm}^{-1}}$ ratio across the tissue specimen, Fig. 3(c), and is a more specific marker to connective tissue than the protein amide $\mathrm{I}\left(\sim 1650 \mathrm{~cm}^{-1}\right)$ band, Fig. 3(d), since protein is abundant within the cell cytoplasm of proliferating $\mathrm{CaP}$ cells as well as $\mathrm{CT}$.

The FAD used to generate the biochemical maps in Figs. 1(d) and 3(c and d), consists of a $64 \times 64$ array of MCT detector elements. Each element collects light from an area of sample $\left(6.25 \times 6.25 \mu \mathrm{m}^{2}\right)$ enabling a $400 \times 400 \mu \mathrm{m}$ section to be imaged at a spatial resolution close to the diffraction limit, in a single shot experiment. The multiplex advantage gained with such an imaging system allows high quality $\mathrm{S} / \mathrm{N}$ spectra to be obtained from specific locations within the tissue.

Nevertheless, this method of extracellullar matrix localisation within malignant areas of an FTIR simulated tissue image is not as specific as immunohistochemical markers for CT on real 




Fig. 2 Photomicrograph taken at low magnification of GG 4 CaP tissue (fused gland formation), histochemically stained with TRI showing collagen and smooth muscle (blue/green) and epithelial tissue (red).

tissue. This is due to the diffraction limit of IR light, which is $5-10 \mu \mathrm{m}$ in the region of most interest, which limits spatial resolution of the IR image. Thus, a spectral map of the $A_{1030 \mathrm{~cm}^{-1}} / A_{1080 \mathrm{~cm}^{-1}}$ values may result in a number of pixels derived from areas consisting of both malignant epithelial cells and CT. Consequently, if the CT influences the malignant cell $A_{1030 \mathrm{~cm}^{-1}} / A_{1080 \mathrm{~cm}^{-1}}$ value, a distorted spectral image of malignant areas within the tissue can result.

The IR data presented in the preceding sections of this paper are acquired from instrumentation incorporating a single point detector (SPD), which is common to most laboratory FITR instruments. The area of tissue that the SPD detects and its ability to acquire high S/N spectra from a sample is primarily due to the aperture size of the objective through which the IR beam is passed. Using a SPD, the effect of CT intrusion upon the $A_{1030 \mathrm{~cm}^{-1}} / A_{1080 \mathrm{~cm}^{-1}}$ values of malignant cells was evaluated. An aperture of $198 \times 72 \mu \mathrm{m}^{2}$ was used to obtain several IR spectra as it was moved in small increments (14 zones), using a digitally controlled micrometer stage, from a region comprising of solely CT (zone 1) into a location of densely populated CaP cells (zone 14), Fig. 4. The $A_{1030 \mathrm{~cm}^{-1}} / A_{1080 \mathrm{~cm}^{-1}}$ values and peak intensity ratio values of $I_{1080 \mathrm{~cm}^{-1}} / I_{1240 \mathrm{~cm}^{-1}}$ were measured at each zone and plotted against the approximate CT coverage within the aperture, Fig. 5.

In Fig. 5 we acknowledge a relationship of increasing $A_{1030 \mathrm{~cm}^{-1}} / A_{1080 \mathrm{~cm}^{-1}}$ value with increasing $\% \mathrm{CT}$ coverage. At $0 \% \mathrm{CT}$, the aperture is solely composed of CaP cells, hence the $A_{1030 \mathrm{~cm}^{-1}} /$ $A_{1080 \mathrm{~cm}^{-1}}$ value is 0.34 and correlates with the diagnostic parameter outlined for malignancy. ${ }^{12}$ The $A_{1030 \mathrm{~cm}^{-1}} / A_{1080 \mathrm{~cm}^{-1}}$ values below $68 \% \mathrm{CT}$ change only slightly (a standard deviation of 0.04 ) relative to those obtained above 68\% CT (a standard deviation of 0.64 ) which indicates that above this inflexion point, CT absorbencies predominate within the band region $1000 \mathrm{~cm}^{-1}$ to $1140 \mathrm{~cm}^{-1}$. Based on these results, we may concur that spectral imaging of the $A_{1030 \mathrm{~cm}^{-1}} / A_{1080 \mathrm{~cm}^{-1}}$ values, using an FAD can be influenced by CT intrusion. However, this occurs if there is less than $32 \%$ cell coverage within any given $6.25 \times 6.25 \mu \mathrm{m}^{2}$ area of tissue. This result is encouraging for IR imaging of malignancy within prostate tissue.

As we would expect, the peak intensity ratio of $I_{1080 \mathrm{~cm}^{-1}} / I_{1240 \mathrm{~cm}^{-1}}$ is inversely correlated to the $A_{1030 \mathrm{~cm}^{-1}} / A_{1080 \mathrm{~cm}^{-1}}$ with increasing $\% \mathrm{CT}$, Fig. 5, and confirms that a steady increase in cellular coverage is detected within the aperture as it is moved across from zones 1 to 14 .

Histopathology of Gleason graded CaP tissue. IR spectra were recorded from epithelial cells at different locations (denoted by the squares in Fig. 6) within each GG specimen. GGs relate to the glandular architecture present in the tissue sections. At GG2, Fig. 6(b), we observe relatively round 

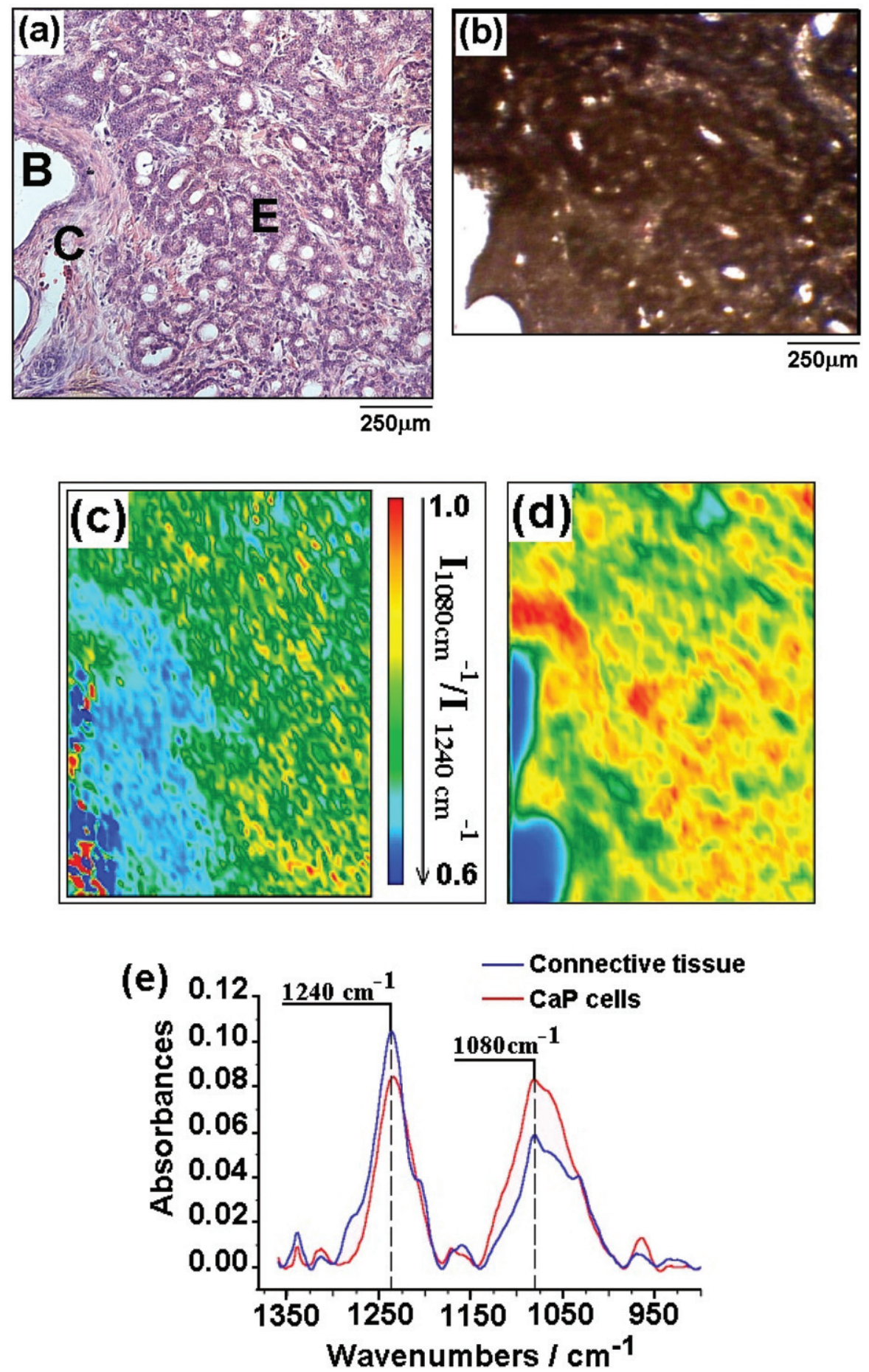

Fig. 3 (a) H\&E section of prostate tissue exhibiting a benign atrophic gland, B, and epithelial cells of GG $4 \mathrm{CaP}, \mathrm{E}$, separated by CT, C. (b) Phase contrast image of serial section mounted onto $\mathrm{BaF}_{2}$ for FTIR imaging. (c) $I_{1080 \mathrm{~cm}^{-1}} / I_{1240 \mathrm{~cm}^{-1}}$ spectral IR map (low $I_{1080 \mathrm{~cm}^{-1}} / I_{1240 \mathrm{~cm}^{-1}}$ values indicate CT). (d) Protein amide I image shows less specificity to CT. (e) IR spectra extracted from pixels in (c) to show differences in peak intensities at $1080 \mathrm{~cm}^{-1}$ and $1240 \mathrm{~cm}^{-1}$ in CT (blue) and CaP cells (red). The ratio of these peaks is used as a marker for CT. 
(a)



(b)
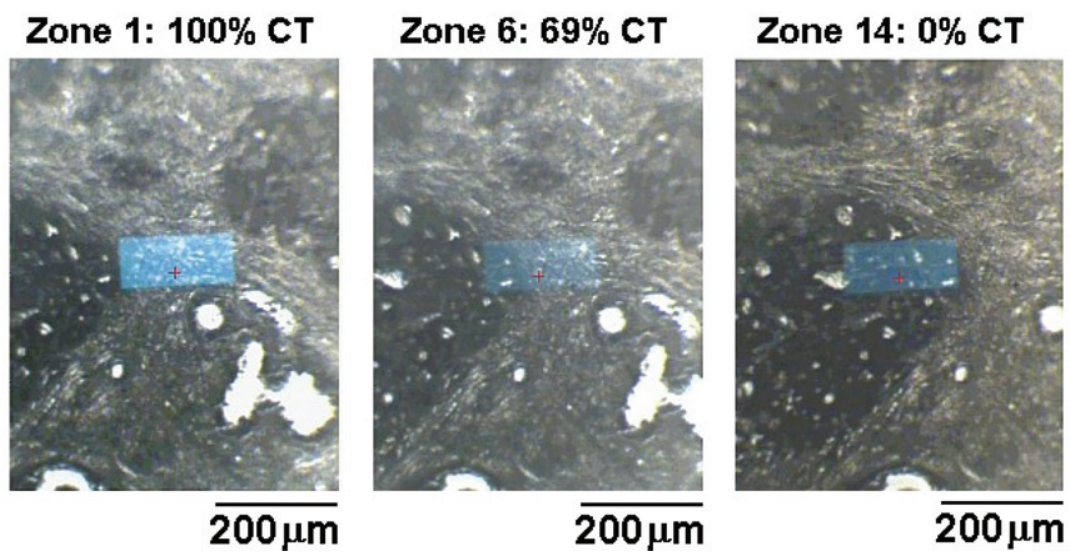

Fig. 4 (a) H\&E stained prostate tissue section showing CT and cellular components. (b) Complimentary, serial tissue section for FTIR analysis. Phase contrast images show a blue rectangle that represents an IR sampling area of $198 \times 72 \mu \mathrm{m}^{2}$ from which a spectrum was recorded with a varying ratio of connective tissue:CaP cells as probed from zones 1 to 14 (selected zones illustrated, see text for discussion). Lighter shaded areas represent $\mathrm{CT}$ and darker shaded areas represent $\mathrm{CaP}$ cells.

malignant glands that are uniform in size and spacing. The glands are separated by fibrocollagenous protein as the main component in the supporting connective tissue. In GG3, Fig. 6(c), the malignant glands are less uniform in size and contour with variable amounts of connective tissue between them. GG4, Fig. 6(d), demonstrates a closer packing of glands with a loss of intervening connective tissue. Finally, GG5, Fig. 6(e), shows a tumour growing in undifferentiated sheets with no gland formation. All malignant glands show a loss of basal cells. A normal prostate gland is shown for comparison in Fig. 6(a).

Construction and model performance of a prototype FTIR-LDA diagnostic algorithm for CaP diagnosis. Although, the $A_{1030 \mathrm{~cm}^{-1}} / A_{1080 \mathrm{~cm}^{-1}}$ values may be used to distinguish between normal, benign and malignant prostate epithelial cells, it can not however, discriminate between the different severities of malignancy. ${ }^{12}$ For this reason we have applied a discriminative chemometric approach, linear discriminant analysis (LDA), to 25 IR spectra recorded from Gleason graded (two to five) prostate tissue. The advantage of using LDA for the classification of IR spectra of different tissue groups is that both the intensity (increase or decrease of biochemical components) and wavenumber shifts (monitoring the bonding nature of biochemical components) of IR peaks and combinations of these peaks, in each group, are considered together. 


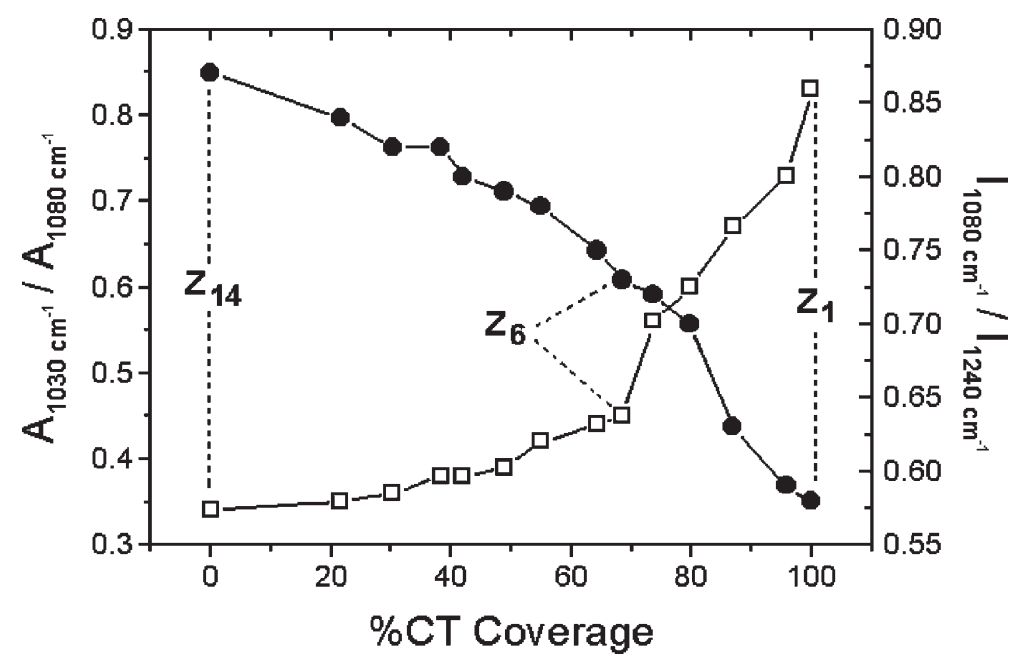

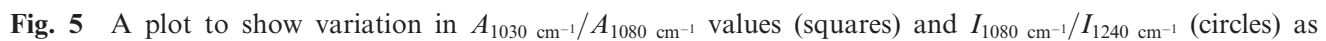
a function of $\% \mathrm{CT}$ coverage. $Z_{1,6,14}$ represents the zones from which these data coordinates were acquired, see Fig. 2(b).

LDA is a supervised method of neural networking, therefore each training spectrum was assigned a grouping number which correlates to the histological specimen from which it was recorded. LDA then attempts to find linear combinations of variables, for a given set of predictors (intensity at each wavenumber), that best separate the groups of spectra. These combinations are termed as discriminant functions. Function 1 separates the groups as far as possible. Function 2 is uncorrelated with function 1 and further separates the groups, the result of which allows for maximal variance between groups and minimal variance within groups. Thus, a cluster plot is generated and can be considered as a prototype diagnostic classifier, which we designate as template 1.

Template 1 is shown in Fig. 7 together with the mean IR spectra taken from each spectral data set used to train each GG cluster. Fig. 7(b) shows the diagnostic spectral region which excludes the

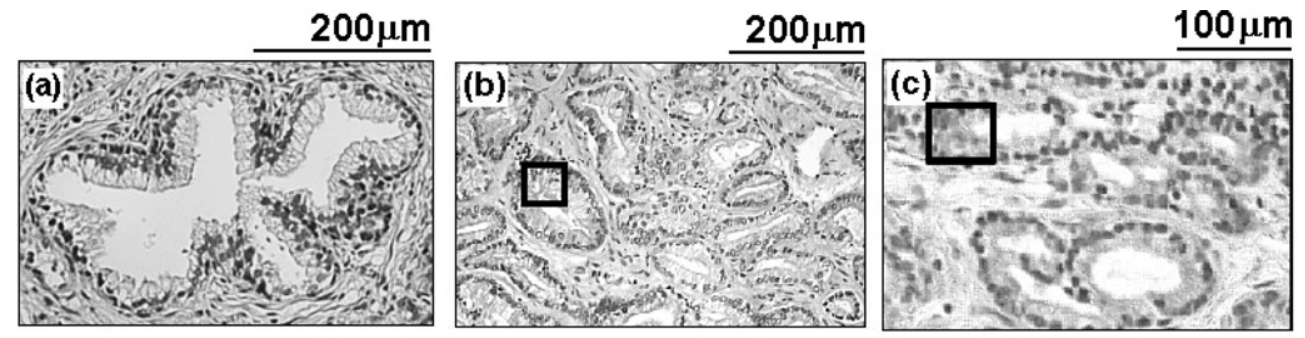

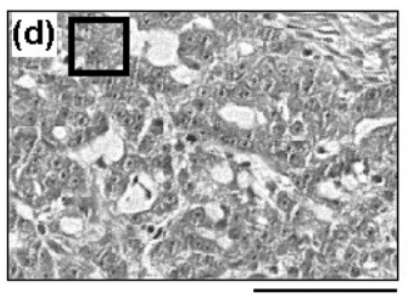

$150 \mu \mathrm{m}$

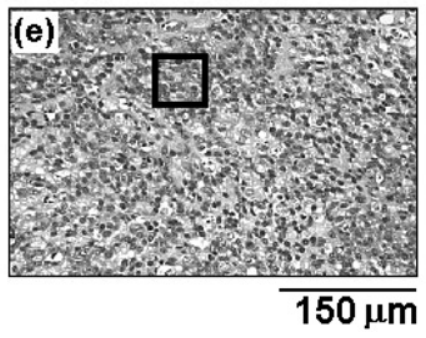

Fig. 6 Photomicrographs of (a) normal prostate gland; (b) GG2; (c) GG3; (d) GG4; (e) GG5. The small squares represent apertures of $60 \times 60 \mu \mathrm{m}^{2}$ from which a typical IR spectrum was recorded at different locations within each specimen. 

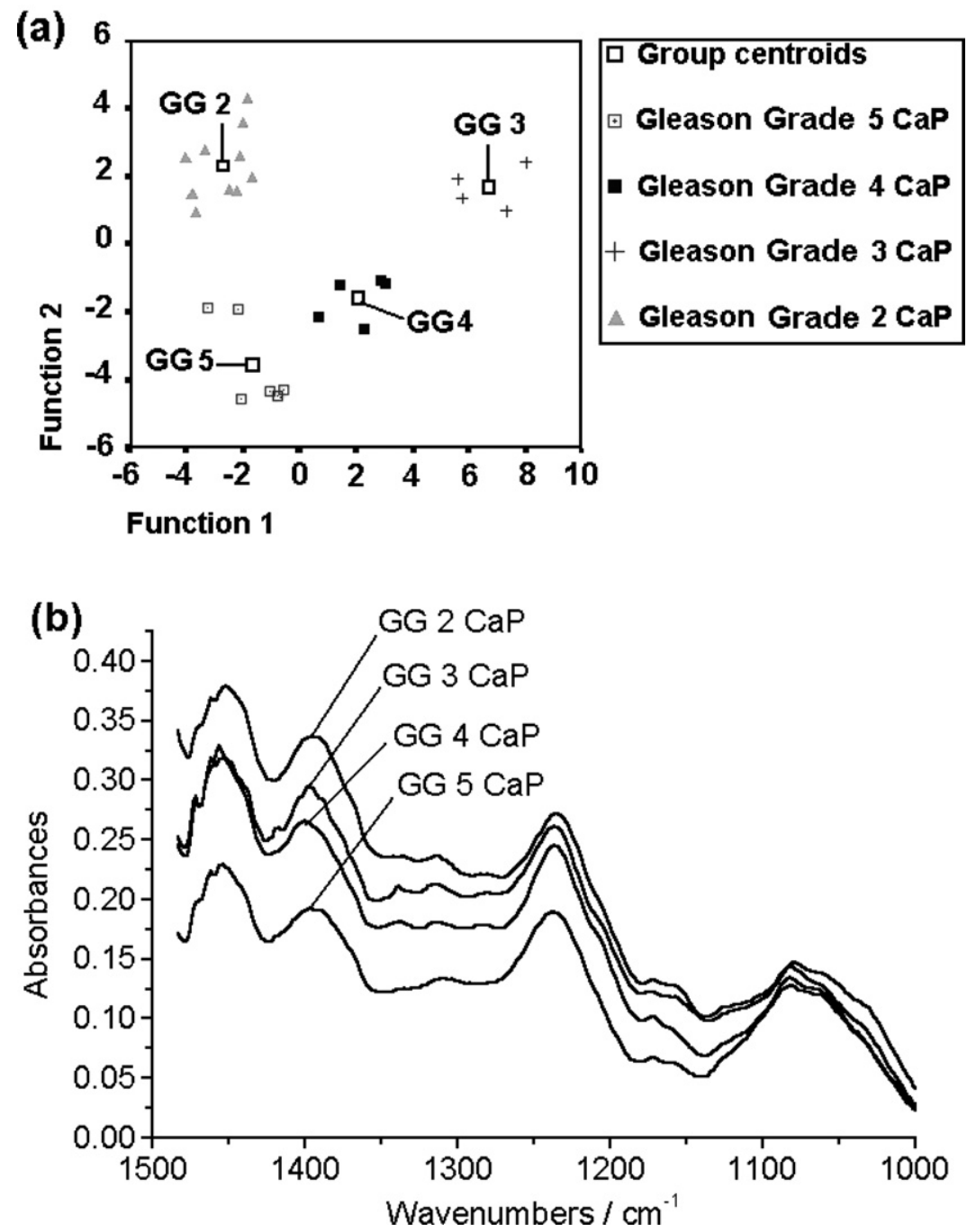

Fig. 7 (a) Template 1, a potential molecular classifier for CaP based upon GG: combined-groups plot of linear discriminant function weights for FTIR spectra. (b) Mean IR diagnostic spectral patterns in band region 1480 $\mathrm{cm}^{-1}$ to $1000 \mathrm{~cm}^{-1}$ recorded from malignant epithelial cells of Gleason graded (two to five) tissue used to train template 1 .

protein amide I and II bands at $\sim 1650 \mathrm{~cm}^{-1}$ and $\sim 1540 \mathrm{~cm}^{-1}$, since inclusion of these intense broad peaks reduces the spectral resolution of the remaining IR bands within the band region 1480 $\mathrm{cm}^{-1}$ to $1000 \mathrm{~cm}^{-1}$. Table 1 shows the biochemical assignments for the IR peaks within this diagnostic spectral region.

A blind test was carried out to assess the model's performance with regard to whether the clusters generated in template 1 are representative of each Gleason graded disease state. In the blind test, IR spectra are recorded from different locations within each Gleason graded CaP tissue, which are taken from biopsies of different $\mathrm{CaP}$ patients that are not used to define the same grade in the training data set. IR spectra used in the blind test were baseline corrected, normalised to the amide I peak at $\sim 1650 \mathrm{~cm}^{-1}$, averaged and then entered into template 1 as an unknown group. The resulting combined groups plot was used to assign the spectroscopic grade of the unknown by determining the minimum Euclidean distance to any one of the pre-defined groups. In addition, single spectrum designations, taken from each tissue specimen, were also assigned. 
Table 1 Assignment of vibrational bands in the diagnostic spectral region $1480 \mathrm{~cm}^{-1}$ to $1000 \mathrm{~cm}^{-1}$

\begin{tabular}{lll}
\hline Wavenumber $/ \mathrm{cm}^{-1}$ & Assignment & Biochemical Assignment \\
\hline 1476 & $\delta_{\text {as }} \mathrm{CH}_{2}$ & \\
1380 & $\delta_{\mathrm{s}} \mathrm{CH}_{3}$ & Glycoproteins and acyl chain of lipids \\
1240 & $\nu_{\text {as }} \mathrm{PO}_{2}^{-}$ & Phosphodiester of nucleic acids, phosphorylated proteins and lipids \\
1230 & $\mathrm{Amide}$ III & Protein \\
1170 & $\nu_{\text {as }} \mathrm{CO}-\mathrm{O}-\mathrm{C}$ & \\
1155 & $\delta_{\mathrm{s}} \mathrm{C}-\mathrm{O}$ & Carbohydrates \\
1120 & $\mathrm{RNA}$ & RNA \\
1080 & $\nu_{\mathrm{s}} \mathrm{PO}_{2}^{-}$ & Phosphodiester of nucleic acids, phosphorylated proteins and lipids \\
1050 & $\nu_{\mathrm{s}} \mathrm{CO}-\mathrm{O}-\mathrm{C}$ & \\
1030 & $\nu_{\mathrm{s}} \mathrm{C}-\mathrm{O}$ & Carbohydrates \\
\hline
\end{tabular}

In total 72 spectra were acquired from 8 biopsies. These 72 spectra were spectroscopically graded by template 1 and the results are shown in Table 2 .

In Table 2, we observe 100\% agreement to histology of FTIR-LDA grade (average spectrum designation) in those specimens that were given a single histological grade. Those specimens that did not show agreement of FTIR-LDA grade to histological grade are locations within cases 2 and 6. Both of these cases have been assigned two histological GGs within the tissue specimen. It is important to note at this juncture that Gleason grading is based solely on tissue architecture, we may consider this as an indirect variable that is associated with the LDA algorithm. The direct variable entered into LDA is associated with spectroscopic differences derived from changes in cytological features such as nucleus-to-cytoplasm ratio, pleomorphism (variation in size and shape of the cell) and biochemical composition. Thus, the GG3 location in case 2 may have been assigned spectroscopically as GG4 as it may be on the more aggressive side of its GG3 "biochemical scale". Encouragingly, we observe that the GG4 location in the same case is correctly classified in template 1. This may support the view that the GG3 location within this specimen may contain biochemical features of cells that have progressed to GG4 biochemistry without glandular transformation. This hypothesis may also be applied to case 6, in which the GG4 location has been spectroscopically designated to GG5, which is also present, histologically, in this tissue section.

For case 3 a single histological assignment was made (GG5). However FTIR-LDA elucidates two grades (GG4 and GG5). These result indicates that although within this specimen the algorithm acknowledges two grades, correlation to the histological given grade is major (high power correlation) with a minor (low power correlation) correlation to a "secondary" grade that is of one value lower/higher. The existence of the primary and secondary GG is reported in current histopathological practices to diagnose patients, whereby the primary grade predominates to a greater

Table 2 FTIR-LDA diagnostic algorithm; model performance by blind testing using template 1

\begin{tabular}{|c|c|c|c|c|c|c|c|c|}
\hline \multirow{2}{*}{$\begin{array}{l}\text { Case } \\
\text { number }\end{array}$} & \multirow[b]{2}{*}{ Histology } & \multirow{2}{*}{$\begin{array}{l}n=\text { Total } \\
\text { spectra }\end{array}$} & \multicolumn{5}{|c|}{ FTIR-LDA GG/single spectrum designation } & \multirow{2}{*}{$\begin{array}{l}\text { FTIR-LDA } \\
\text { GG/average } \\
\text { spectrum } \\
\text { designation }^{b}\end{array}$} \\
\hline & & & GG 2 & GG 3 & GG 4 & GG 5 & Unclassified $^{a}$ & \\
\hline 1 & GG 2 & 8 & 6 & & & & 2 & GG 2 \\
\hline \multirow[t]{2}{*}{2} & GG 3 & 4 & & & 4 & & & GG 4 \\
\hline & GG 4 & 9 & & & 9 & & & GG 4 \\
\hline 3 & GG 5 & 6 & & & 1 & 5 & & GG 5 \\
\hline 4 & GG 4 & 10 & & & 9 & & 1 & GG 4 \\
\hline 5 & GG 5 & 5 & & & & 3 & 2 & GG 5 \\
\hline \multirow[t]{2}{*}{6} & GG 4 & 8 & & & 2 & 5 & 1 & GG 5 \\
\hline & GG 5 & 7 & & & & 6 & 1 & GG 5 \\
\hline 7 & GG 2 & 5 & 4 & & & & 1 & GG 2 \\
\hline 8 & GG 5 & 10 & & & & 9 & 1 & GG 5 \\
\hline
\end{tabular}



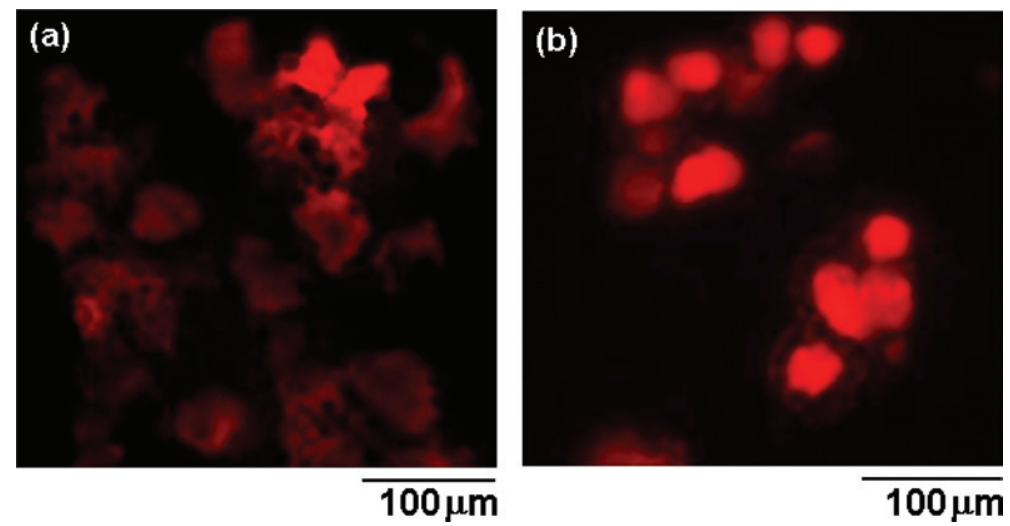

Fig. 8 Nucleic acid staining of prostate cancer cells on (a) top shard and (b) bottom steel substrate of sandwich, following freeze fracture. Fluorescent photomicrographs taken at $\times 200$ magnification.

extent within the tissue specimen than the secondary grade. In cases where the tissue specimen exhibits only one GG, the GG is doubled. Therefore, the same criteria can be also used to spectroscopically diagnose patients on the basis of single spectrum designations.

\section{ToF-SIMS analysis of PC-3 cells}

In the following text we report our preliminary ToF-SIMS findings of fractured and unfractured PC-3 cells. The freeze fracture of a cell results in a number of surfaces that may be exposed and available for ToF-SIMS analysis. Fig. 8 shows fluorescent images of propidium iodide stained

(a) Total lon

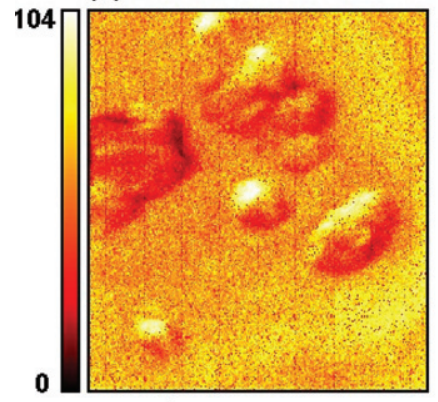

(d) $\mathrm{Ca}^{+}$

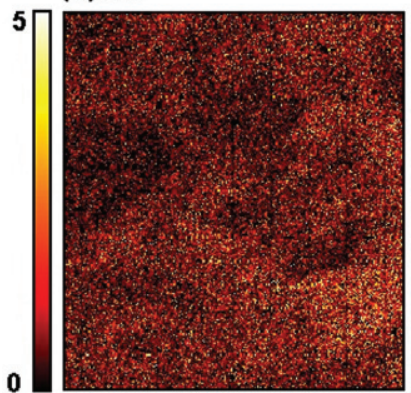

(b) $\mathrm{Na}^{+}$

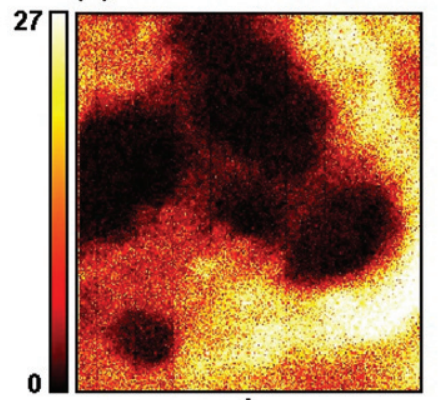

(e) $m / 2[184]^{+}$

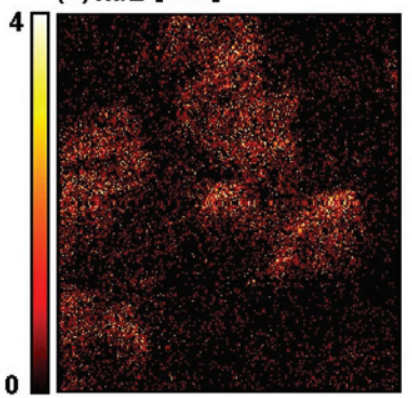

(c) $\mathrm{K}^{+}$

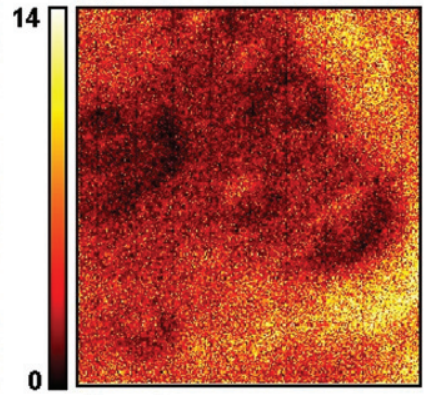

(f) $\mathrm{Si}^{+}$

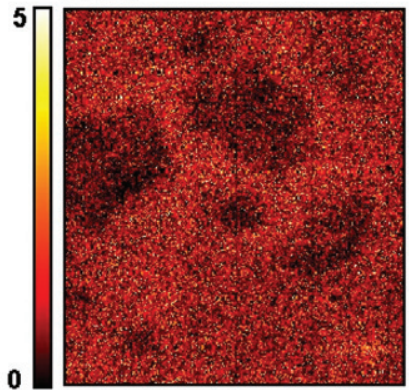

Fig. 9 Positive ion ToF-SIMS images of unfractured PC-3 cells upon a Si substrate. (a) Total ion image and (b)-(f) secondary ion extracted images of $\mathrm{Na}^{+}, \mathrm{K}^{+}, \mathrm{Ca}^{+}, m / z[184]^{+}$(PC head group), $\mathrm{Si}^{+}$(culture substrate) respectively. All images are $150 \mu \mathrm{m}$ wide-f.o.v. Colour intensity scales are displayed next to image. 
(a) Total ion

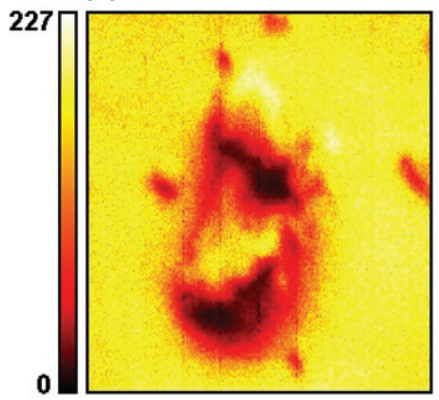

(d) $\mathrm{Ca}^{+}$

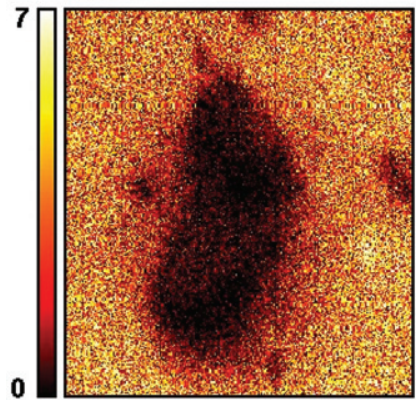

(b) $\mathrm{Na}^{+}$

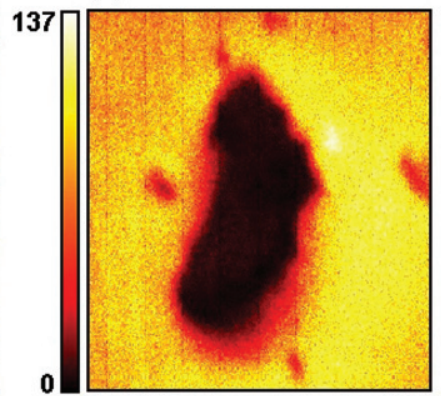

(e) $m / z[184]^{+}$

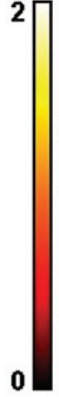

(c) $\mathrm{K}^{+}$

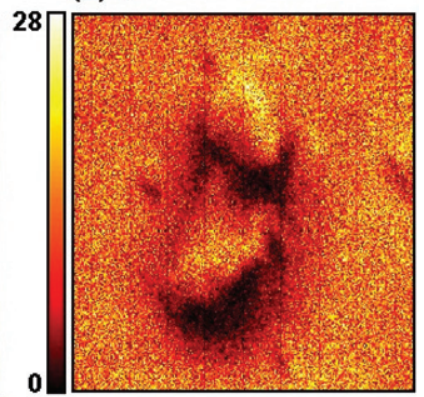

(f) $\mathrm{Fe}^{+}$

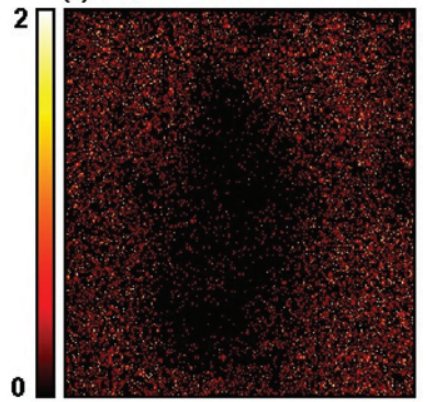

Fig. 10 Positive ion ToF-SIMS images of two fractured PC-3 cells upon a steel substrate. (a) Total ion image and (b)-(f) secondary ion extracted images of $\mathrm{Na}^{+}$(0 to 50418 counts), $\mathrm{K}^{+}, \mathrm{Ca}^{+}, m / z$ [184] ${ }^{+}$(PC head group), $\mathrm{Fe}^{+}$(culture substrate), respectively. All images are $100 \mu \mathrm{m}$ wide-f.o.v. Colour intensity scales are displayed next to image.

(nucleic acid stain) prostate cancer cells on the top and bottom substrates of the steel sandwich after fracture. The top shard, Fig. 8(a), contains many cell sections exhibiting little or no nucleic acid fluorescence. This can be representative of either the inner or outer leaflet of the cell membrane. In contrast, the bottom (cell culture) substrate contains a relatively large number of distinct cellular fragments exhibiting fluorescence, suggesting cross-fractured and/or intact cells.

Characteristic mass fragments of cellular sections can be identified in the ToF-SIMS spectrum and have been reported by Roddy et al. ${ }^{19}$ The ToF-SIMS images of unfractured (clustered and individual) PC-3 cells and two fractured PC-3 cells are shown in Figs. 9 and 10, respectively. The localisation and emission intensities of the secondary ions selected for imaging in Figs. 9 and 10 enables a preliminary assessment to whether a cell has been successfully fractured.

The $\mathrm{Na}^{+} / \mathrm{K}^{+}$intensities in both the intact and fractured cells are low indicating well preserved cells. Additionally, since the $\mathrm{Na}^{+}-\mathrm{K}^{+}$pumps in the plasma membrane maintains an intercellular $\mathrm{K}^{+} / \mathrm{Na}^{+}$concentration of approximately $10: 1{ }^{23}$ we observe a higher emission of $\mathrm{K}^{+}$within the fractured cell, Fig. 10(c), indicating that the cytoplasm is indeed exposed for analysis. Another key characteristic feature of preserved cells is the total free and unbound, intercytoplasmic concentration of $\mathrm{Ca}$. The $\mathrm{Ca}$ pumps in the plasma membrane of eukaryotic cells maintain a steep $\mathrm{Ca}$ gradient resulting in an intercellular (free ionised) concentration of $\sim 10^{-7} \mathrm{M}$ in contrast to $\sim 10^{-3} \mathrm{M}$ in the extracellular matrix. ${ }^{24} \mathrm{This}$ coincides with the $\mathrm{Ca}^{2+}$ ion emissions observed for the unfractured and fractured PC-3 cells in Figs. 9(d) and $10(\mathrm{~d})$, respectively. The low $\mathrm{Ca}^{2+}$ signal that is observed within the fractured cell can arise from a number of $\mathrm{Ca}^{2+}$ stores such as calciosomes, mitochondria, endoplasmic reticulum (ER), Golgi apparatus, cell nucleus and $\mathrm{Ca}$ binding proteins, all of which regulate intercellular Ca levels upon physiological stimuli. ${ }^{25-30}$

The surface of an intact animal cell consists of a lipid bilayer (approximately $10^{6}$ lipid molecules in a $1 \mu \mathrm{m} \times 1 \mu \mathrm{m}$ area of lipid bilayer) of which, phospholipids constitute $50 \%$ of the lipid 

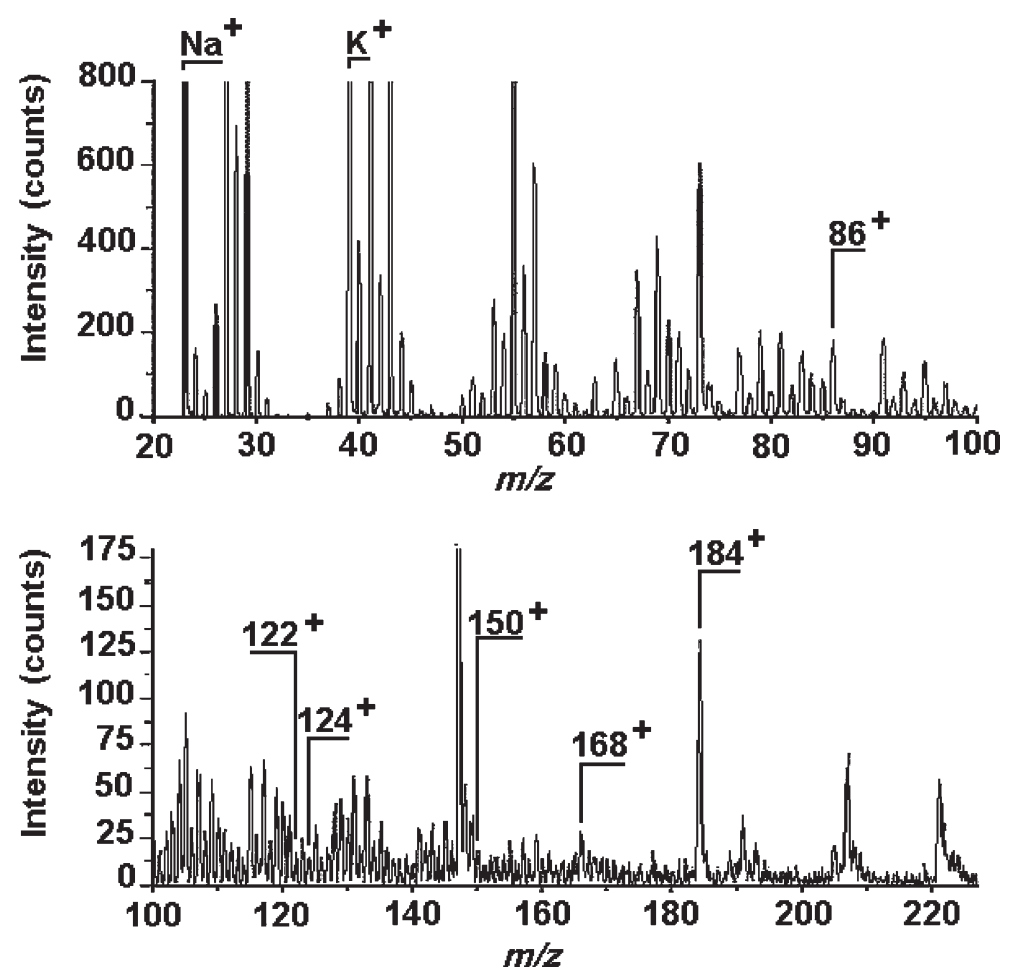

Fig. 11 Positive ion ToF-SIMS spectrum of pixels corresponding to unfractured PC-3 cells. The intensity scale is expanded to show low emitting secondary ions.

component and surround membrane proteins. ${ }^{31}$ Of the four major classes of phospholipids, phosphatidylcholine (PC) is the most abundant and its head group gives rise to species at $\mathrm{m} / \mathrm{z}$ $[184]^{+}$and $[86]^{+}$in the ToF-SIMS spectrum. ${ }^{18}$ Fig. 9(e) shows high emission of $m / z[184]^{+}$on the surface of the unfractured cells as expected. In contrast, PC emissions from within the fractured cells are relatively low and arise due to its presence in membrane components of cytoplasmic organelles, mainly ER and mitochondria, Fig. 10(e).

Secondary ion images characteristic of the cell culture substrate are presented which clearly distinguish areas of cellular material, Figs. 9(f) and 10(f).

Each pixel in the ToF-SIMS image corresponds to a mass spectrum, permitting cellular specific mass spectra to be extrapolated. These are presented in Figs. 11 and 12, corresponding to the intact and fractured cells, respectively. As discussed earlier, the PC ion intensities at $m / z[184]^{+}$and $[86]^{+}$ are barely observable in the fractured cells in contrast to the intact cell spectrum. However, we find that the peak at $m / z[168]^{+}$in the fractured cells has significantly risen in intensity. We suggest that the peaks at $m / z[168]^{+}$and $m / z[124]^{+}$may be characteristic fragments of the phosphatidylethanolamine (PE) head group, Fig. 13(a).

It is well known that the lipid composition of the inner and outer leaflet of the lipid bilayer differ significantly in different cell types ${ }^{31}$ and phospholipid molecules that contain a terminal primary amino group (PE and phosphatidylserine) locate preferentially within the inner cell membrane. ${ }^{32} \mathrm{In}$ the light of this information and in correlation to the ToF-SIMS images of $\mathrm{m} / z[168]^{+}$and $\mathrm{m} / z$ $[124]^{+}$with $\mathrm{K}^{+}, \mathrm{Ca}^{+}$and $\mathrm{PC}$ fragments, we suggest that this fracture area comprises two distinct fracture planes. The area denoted by the green boxes in Fig. 13(b) represents cell membrane material with an absence of cytoplasm, since the $\mathrm{K}^{+}$and $\mathrm{Ca}^{+}$images are not observed within this region. The areas that do show $\mathrm{K}^{+}$and $\mathrm{Ca}^{+}$localisation may represent inner-leaflet material derived from either plasma membrane in contact with cytoplasm or cytoplasmic organelles. In addition, an overlay of $\mathrm{K}^{+}$with $m / z[168]^{+}$, Fig. 13(b), reveals that $m / z[168]^{+}$is localised towards 


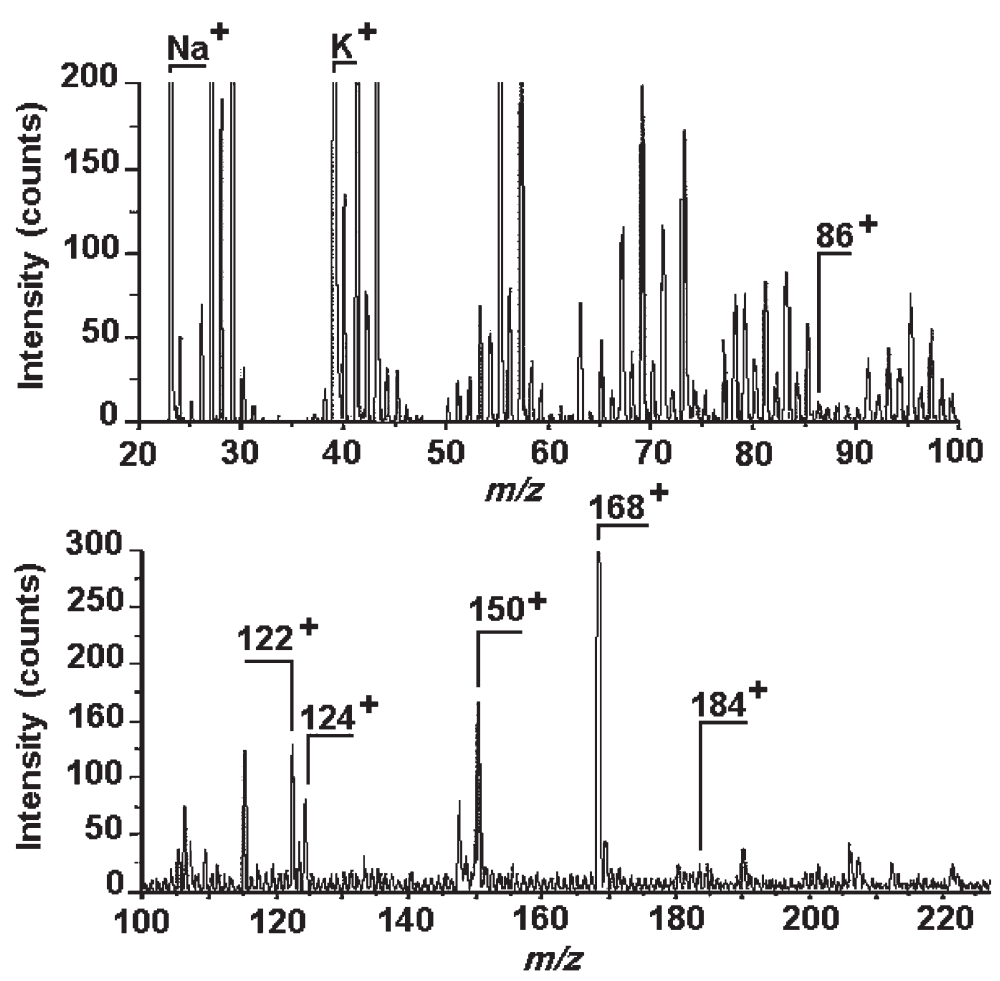

Fig. 12 Positive ion ToF-SIMS spectrum of pixels corresponding to fractured PC-3 cells. The intensity scale is expanded to show low emitting secondary ions.

the outer edges of the fractured cells (solid arrows) with an absence of $\mathrm{K}^{+}$at these areas which is consistent with features of a fractured cell. The peaks at $m / z[122]^{+}$and $[150]^{+}$were observed to be co-localised within regions of $m / z[168]^{+}$and $m / z[124]^{+}$suggesting they are also related to membrane bound material.

In both the fractured and unfractured cell mass spectra, polydimethylsiloxane (PDMS) peaks at $m / z[73]^{+},[147]^{+},[207]^{+}$and $[221]^{+}$are observed. PDMS is a common contaminant in SIMS experiments. Its presence may be associated with cell culture apparatus, polystyrene microspheres added as spacers for sandwich fracturing or abrasion of specimens against the sides of the cryovials in which they were stored.

An interesting feature observed within the fractured PC-3 cell is the co-localisation of $m / z[63]^{+}$ and $[65]^{+}$shown in Fig. 14. From the total ion SIMS spectrum we observe a $m / z[63]^{+}:[65]^{+}$count of 1.9. The isotopic weights for these peaks correspond to ${ }^{63} \mathrm{Cu}$ and ${ }^{65} \mathrm{Cu}$ whose ratio of relative abundances is 2.2 . This may identify peaks at $m / z[63]^{+}$and $[65]^{+}$as $\mathrm{Cu}$, with slight differences in the ratio of isotopic abundances due to isobaric interferences. In the cell, $\mathrm{Cu}$ is an essential cofactor for many enzymatic activities and has been associated with increasing the risk of metastasis for cancer cells by mediating angiogenesis. ${ }^{33}$ In this present study, we observe a distinct localisation of $\mathrm{Cu}$ from within the cytoplasm of the PC-3 cell and requires further investigation to determine whether this is a common feature across all cell types or unique to the PC-3 cell line. The question arises to whether $\mathrm{Cu}$ is present as an endogenous source within the cells or is incorporated into the cells during culture. The latter of the two may be more significant as the nutrient medium, Ham's F12, contains $\mathrm{CuSO}_{4}$ and is localised homogenously upon the substrate.

Similarly to $\mathrm{Cu}$ localisation, we observe a heterogeneous distribution of ${ }^{24} \mathrm{Mg}$ within the fractured cell, Fig. 15. Its uptake into the PC-3 cells may again arise from the culture medium, which contains $\mathrm{MgCl}_{2}$ and is observed to be homogenously localised upon the steel substrate. Within the cell, $\mathrm{Mg}$ is the second most abundant cation of which $90 \%$ is bound to nucleic acids, negatively charged phospholipids, proteins and ATP. ${ }^{34}$ Wolf et al. have suggested that $\mathrm{Mg}$ 


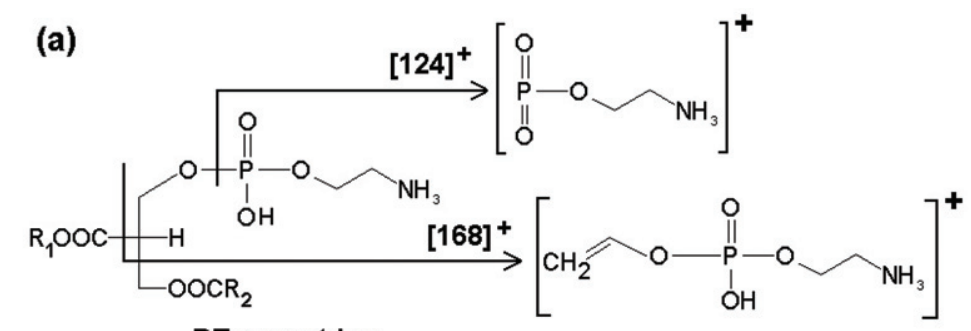

(b)

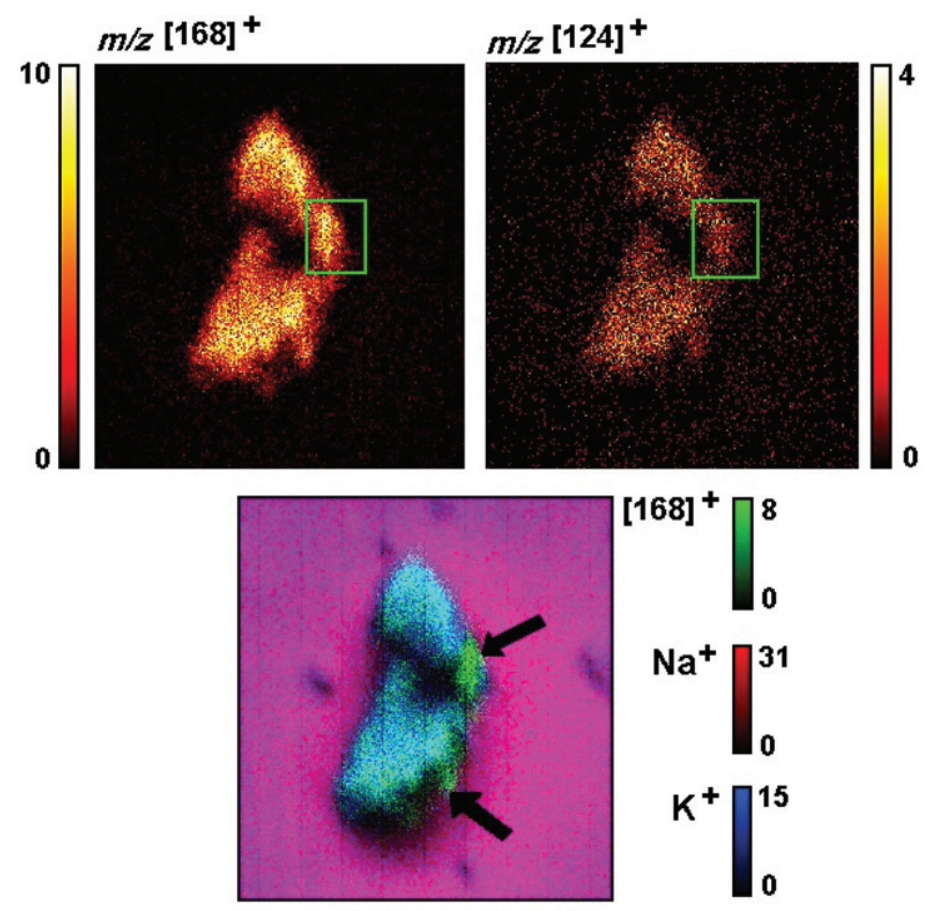

Fig. 13 (a) Structure of PE and possible cleavage points to give rise to postulated head group fragments, $m / z$ $[168]^{+}$and $[124]^{+}$observed in the positive ion ToF-SIMS spectrum of fractured PC-3 cells. $\mathrm{R}_{1}$ and $\mathrm{R}_{2}$ represent the $\mathrm{C}_{16} \mathrm{H}_{31}$ fatty acid chains of PE. (b) ToF-SIMS images of $m / z[168]^{+}$and [124] $]^{+}$exhibit co-localisation in areas of $\mathrm{K}^{+}$depression (see Fig. 11), indicated by green boxes. An overlay of $\mathrm{Na}^{+}$(red), $m / z$ [168] ${ }^{+}$(green) and $\mathrm{K}^{+}$(blue), shows high secondary ion emissions of $m / z[168]^{+}$from outer edges of fractured cells (solid arrows). All images are $100 \mu \mathrm{m}$ wide-f.o.v. Colour intensity scales are displayed next to image.

compartmentalization is a function of the metabolic demands of the cell, for example, dividing cells that synthesise more DNA show an increase in nuclear Mg. ${ }^{35}$ In the ToF-SIMS image shown in Fig. 15 it is not possible to evaluate at this stage the precise organelle to which $\mathrm{Mg}$ has accumulated. However, together with the observed $\mathrm{Cu}$ localisation, we acknowledge intercellular domains within the PC-3 cell that selectively accumulate substantial concentrations of more of one ion type than another.

\section{Conclusions}

Using a single point detector we have demonstrated that connective tissue absorption can affect the $A_{1030 \mathrm{~cm}^{-1}} / A_{1080 \mathrm{~cm}^{-1}}$ values if there is less than $\sim 30 \%$ cellular coverage within the sampling area. This result is encouraging for IR imaging purposes of benign and malignant locations within a tissue specimen. The biochemical map of the $A_{1030 \mathrm{~cm}^{-1}} / A_{1080 \mathrm{~cm}^{-1}}$ values, together with the intensity distribution of $I_{1080 \mathrm{~cm}^{-1}} / I_{1240 \mathrm{~cm}^{-1}}$ values (a marker for connective tissue in this study), can generate 


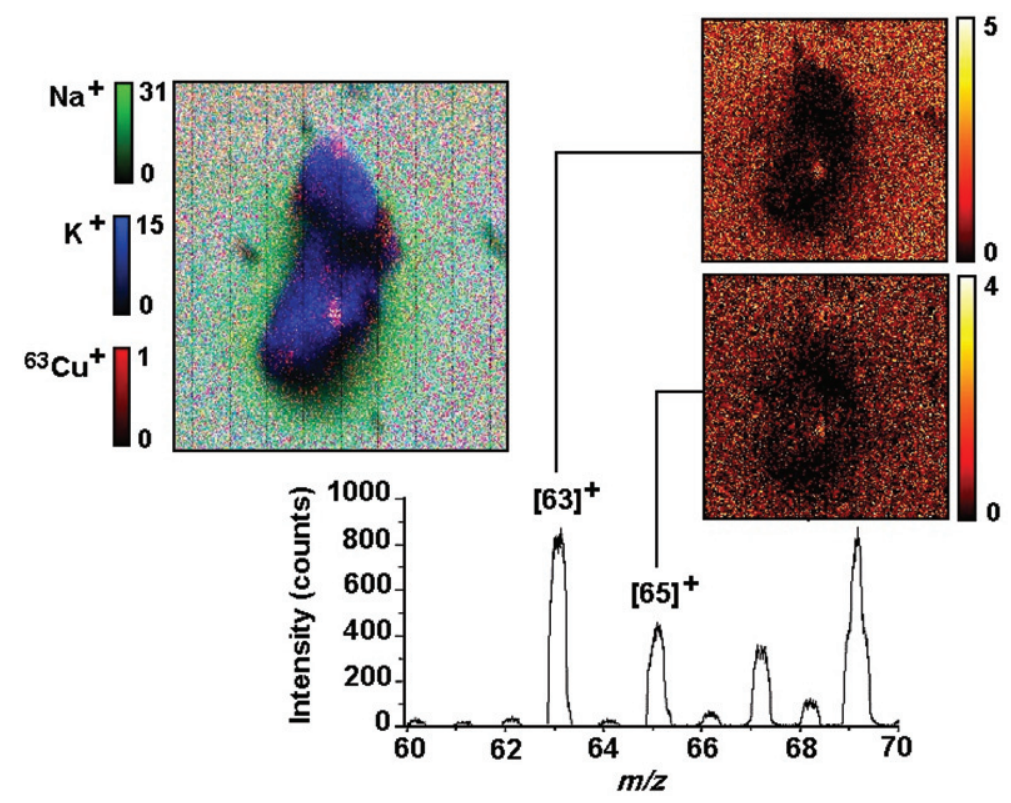

Fig. 14 Positive ion ToF-SIMS spectrum and images revealing co-localisation of $\mathrm{m} / \mathrm{z}[63]^{+}$and $[65]^{+}$, corresponding to ${ }^{63} \mathrm{Cu}$ and ${ }^{65} \mathrm{Cu}$ respectively. An overlay of ${ }^{63} \mathrm{Cu}^{+}$(red), $\mathrm{Na}^{+}$(green) and $\mathrm{K}^{+}$(blue), reveals $\mathrm{Cu}$ localisation within the cytosol of two fractured PC-3 cells. All images are $100 \mu \mathrm{m}$ wide-f.o.v. Colour intensity scales are displayed next to image.

a representative IR simulated image of the tissue section under analysis. We envisage that this IR biochemical map can be used as a potential screening tool, since each IR spectrum taken from malignant pixels can be further processed for diagnostic classification.

We have reported the development of a prototype FTIR-LDA diagnostic classifier for prostate cancer diagnosis, based upon the established Gleason grading system. Preliminary results of the performance of this model demonstrate a good agreement to histology for the specimens studied. However, the Gleason graded specimens studied in this paper have been assigned, in majority, to histological grades GG4 or 5. Work in progress is targeted at increasing the IR database of graded specimens with correlation to clinical variables such as (i) PSA levels prior to biopsy, (ii) medication administered to patient prior to biopsy, (iii) staging data at time of biopsy (TNM), (iv) types of therapy and length of remission.

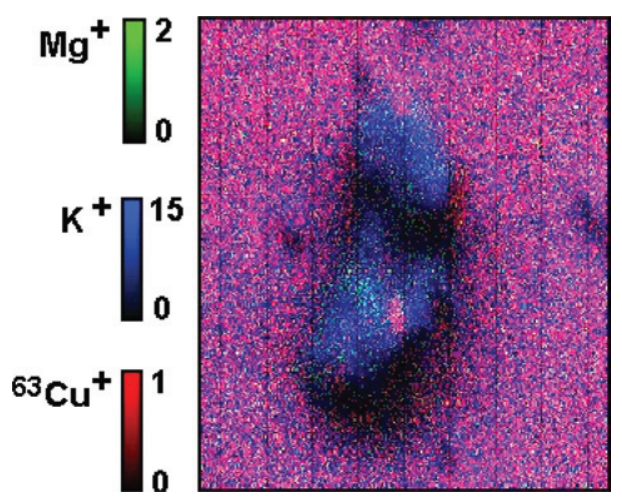

Fig. 15 Positive ion ToF-SIMS image of $\mathrm{Mg}^{+}$(green), $\mathrm{Cu}^{+}$(red) and $\mathrm{K}^{+}$(blue). A discrete localisation of $\mathrm{Mg}^{+}$can be observed towards the left hand side of cytoplasmic $\mathrm{Cu}^{+}$. Image is $100 \mu \mathrm{m}$ wide-f.o.v. Colour intensity scales are displayed next to image. 
The ToF-SIMS data reported here provides the basis for a valuable insight into specific biochemical compositions of the PC-3 cell, identifying both molecular fragments and inorganic ions. We have demonstrated that the exposed surface of a fractured cell may run through different fracture planes, which can be identified on the basis of ToF-SIMS signals.

The information available from ToF-SIMS, in conjunction with FTIR data can provide a unique perspective to the bio-mechanisms of cancer cells. Future experiments will focus upon the uptake of different inorganic ions into prostate cancer cells and whether this will lead to differences in invasive properties. This type of information can be obtained by ToF-SIMS as we have demonstrated with the localisation of copper and magnesium within the cytoplasm of PC-3 cells. Through further work, it can undoubtedly provide the molecular biologist with a focused line of research that may target specific oncoproteins dependent upon specific ions or for the inhibition of specific ion channels that may play a role in cellular proliferation. We have reported elsewhere the separation of metastatic cell lines from BPH and in situ CaP, using FTIR - principle component analysis (PCA). These results suggest that the extent to which clusters are separated from each other may be associated to invasive properties of each cell line. Thus, the cluster plot can be used to determine whether inorganic ions have a negative or positive effect on invasiveness as a consequence of ion uptake, which can be subsequently confirmed and quantified through imaging ToF-SIMS.

\section{Acknowledgements}

We acknowledge EPSRC for financial support (E. Gazi). We gratefully thank Dr Roger Speak for use of FTIR equipment in Manchester University and Dr Gary Ashton and Miss Caron Abbey for the preparation of histological sections. We thank Mr Emrys Jones for technical assistance during ToF-SIMS measurements.

\section{References}

1 Cancer Stats, Mortality-UK. June 2002, Cancer Research UK http://www.cancerresearchuk.org/ images/11632/cancerstats_mortality_2002.pdf accessed 30th October 2002.

2 D. F. Gleason, in Urological Pathology - The Prostate, ed. M. Tannenbaum, Lee and Febiger, Philadelphia, 1977, p. 171.

3 J. I. Epstein, G. Pizov and P. C. Walsh, Cancer, 1993, 71, 3582.

4 G. K. Zagars, A. Pollack and A. C. von Eschenbach, Cancer, 1997, 79, 1370.

5 L. J. Coetzee, L. J. Layfield, V. Hard and D. F. Paulson, J. Urol., 1996, 157, 214.

6 M. Kojima, P. Troncoso and R. J. Babaian, Urology, 1995, 45, 807.

7 R. J. Babaian and W. A. Grunow, Urology, 1985, 25, 564.

8 J. B. Lattouf and F. Saad, BJU Int., 2002, 90, 694.

9 G. D. Carlson, C. B. Calvanese, H. Kahane and J. I. Epstein, Urology, 1998, 51(4), 525.

10 L. Egevad, Urology, 2001, 57(2), 291.

11 C. P. Schultz, Tech. Cancer Res. Treat., 2002, 1(2), 95.

12 E. Gazi, J. Dwyer, P. Gardner, A. Ghanbari-Siahkali, A. P. Wade, J. Miyan, N. P. Lockyer, J. C. Vickerman, N. W. Clarke, J. H. Shanks, L. J. Scott, C. Hart and M. Brown, J. Pathol., 2003, 201, 99-108.

13 J. Tapia-Vieyra and J. Mas-Oliva, Arch. Med. Res., 2001, 32, 175.

14 L. C. Costello and R. B. Franklin, The Prostate, 1998, 35, 285.

15 S. Chandra, C. Fewtrell, P. J. Millard, D. R. Sandison, W. W. Webb and G. H. Morrison, J. Biol. Chem., 1997, 269(21), 15186.

16 S. Chandra and D. R. Lorey II, Cell. Mol. Biol., 2001, 47(3), 503.

17 J.-L. Guerquin-Kern, M. Coppey, D. Carrez, A.-C. Brunet, C. H. Nguyen, C. Rivalle, G. Slodzian and A. Croisy, Microsc. Res. Tech., 1997, 36, 287.

18 D. M. Cannon, M. L. Pacholski, N. Winograd and A. G. Ewing, J. Am. Chem. Soc., 2002, $122,603$.

19 T. P. Roddy, D. M. Cannon Jr., S. G. Ostrowski, N. Winograd and A. G. Ewing, Anal. Chem., 2002, 74, 4020.

20 M. E. Kaighn, K. S. Narayan, Y. Ohnuki, J. F. Lechner and L. W. Jones, Invest Urol., 1979, $17,16$.

21 R. M. Braun, P. Blenkinsopp, S. J. Mullock, C. Corlett, K. F. Willey, J. C. Vickerman and N. Winograd, Rapid Commun.Mass Spectrom., 1998, 12, 1246.

22 The Static SIMS Library, version 3.0.2.19, ed. J. C. Vickerman, D. Briggs and A. Henderson, Surface Spectra Ltd. Manchester, UK.

23 K. J. Sweadner and S. M. Goldin, New Engl. J. Med., 1980, 302, 777.

24 E. Carafoli, Physiol. Rev., 1991, 71, 129. 
25 P. Volpe, K. H. Krause, S. Hashmoto, F. Zorato, T. Pozzan, J. Meldolesi and P. D. Lew, Proc. Natl. Acad. Sci., 1987, 85, 1091.

26 R. Durand, Y. Briand, S. Touraille and S. Alziari, Trends Biochem. Sci., 1981, 6, 221.

27 G. L. E. Koch, Bioessays, 1990, 12, 527.

28 S. Chandra, E. R. Kable, G. H. Morrison and W. W. Webb, J. Cell Sci., 1991, 100, 742.

29 P. Nicoreta, S. Orrenius, T. Nilsson and P. O. Berggren, Proc. Natl. Acad. Sci. USA, 1990, 87, 6858.

30 C. W. Heizmann and W. Hunziker, Trends Biochem. Sci., 1991, 16, 98.

31 G. van Meer, Annu. Rev. Cell Biol., 1989, 5, 247.

32 D. Dalake and W. Huestis, J. Cell Biol., 1989, 108, 1375.

33 Q. Pan, C. G. Kleer, K. L. van Golen, J. Irani, K. M. Bottema, C. B. M. De Carvalho, E. A. Mesri, D. M. Robins, R. D. Dick, G. J. Brewer and S. D. Merajver, Cancer Res., 2002, 62, 4854.

34 J. Vormann, Mol. Aspects Med., 2003, 24, 27.

35 F. I. Wolf, A. Torsello, S. Fasanella and A. Cittadini, Mol. Aspects Med., 2003, 24, 11. 